\title{
Compliance control as the leading technology of tackling corruption in enterprises
}

\author{
Galina Menshikova \\ Faculty of Sociology \\ Saint Petersburg State University \\ Universitetskaya nab. 7/9, 199034, Saint Petersburg \\ Russian Federation \\ e-mail: menshikova.g.a@mail.ru \\ Nikolai Pruel \\ Faculty of Sociology \\ Saint Petersburg State University \\ Universitetskaya nab. 7/9, 199034, Saint Petersburg \\ Russian Federation \\ e-mail: pruijel@inbox.ru \\ Valeriy Malychev \\ Faculty of Sociology \\ Saint Petersburg State University \\ Universitetskaya nab. 7/9, 199034, Saint Petersburg \\ Russian Federation \\ e-mail: ﹎.malychev@mail.ru
}

\begin{abstract}
This paper considers the system of compliance contract as a further development of the theory of the social contract, social interactions and organizational leadership. Moreover, we reveal the similarities and the differences between these two concepts. In our view, compliance control represents a truly leading technology of fighting corruption in enterprises. These issues gain special importance in Russia with its widespread problems and issues such as cronyism and corruption.

In parallel, the paper presents some novel literature overview and own findings that would enable to characterize the problems of the functioning of compliance systems in firms and enterprises in modern conditions both in Russian and abroad. Foreign practice confirms the success of the development of this technology which allows us to consider it as a new social institution that would be able to be used in identifying the stages of the process. All in all, we might conclude that in Russia this practice is still far from being widespread which does not allow it to be viewed as an established social institution.
\end{abstract}

\section{Introduction}

Leadership represents a historically developed and deeply embedded need of people for the organization of their activity. Leadership is the one of the mechanisms of association of group activity when a person or a part of social group carries out a role of the leader, i.e. organizes, directs work of all group which expects, takes and supports her or his actions. Therefore, leadership is the relations of domination and submission, an influence, or the phenomenon of political and public life connected with implementation of imperious functions.

The institute of democratic leadership is a difficult system with the structure and rules of formation. It closely interacts with other social institutes and fully depends on them. Democratic leadership is the institutionalizing institute as within the functions - stabilization and integration institutionally is the important communication medium of the power and society, and also structuring collective actions and defines, thereby limits of existence of other institutes. At the same time, the institute of democratic leadership is influenced by the most various external and internal factors. Among these factors in modern Russia are the carrying out administrative reform and the formation of anti-corruption climate that gain special value.

The analysis of the complexities in the implementation of administrative reforms has exacerbated the importance of addressing ethical issues in general and the development of norms for anti-corruption behavior in particular. It becomes obvious that it was the personal qualities of managers at different levels, as well as the general willingness to obey the norms of ethical behavior, including the active opposition to corruption - that make up the problem zones of the social management system. 
Compliance with the norms of morality has always been perceived as a significant task of social management. The society constantly created social institutions that regulate people's behavior, directing it to the channel of order, observance of the principles of social responsibility and ethical rules. Ethical restrictions were rigidly tabulated by religion, regulated by a constantly improved system of legislative norms and sanctions (in all its diversity) (Ushakov et al. 2017). Modern society, realizing the properties of postmodern, also seeks to persuade (and successfully achieves this) people, their communities within enterprises, institutions of government and administration, that compliance with moral norms is a way of development and selfpreservation, a guarantee of order and common prosperity (Filipishyna et al. 2018).

Preserving former forms of ethical behavior among people: education, ideological conviction, using moral and material incentives/punishments, etc., society creates new ones, reflecting modern possibilities, or (as one can say) embedded in the circumstances of postmodern. Thence, a system of various measures for presentation by people - economic actors - of their readiness for ethically responsible behavior has been developed and is being implemented in practice: codes of conduct and ethical standards are adopted at enterprises, and "regime reports" are formed in countries and regions (Doležal et al. 2015; Bychkova et al. 2018). All of them are related by foreign researchers to compliance technology.

The compliance theory is practically not represented in the Russian scientific field, although in practice, examples of its implementation take place. The purpose of the article is to generalize theoretical studies, revealing their trends and practical potential, and also to describe the institutional milestones in the formation of practices for its implementation abroad and in the Russian Federation.

\section{2 "Compliance" discourse as a modern extension of the theory of social contract and contracts}

Compliance theory is becoming more common, attracting the interests of scientists, and the relationship of reciprocal obligations taken by actors at different levels of social organization is increasingly frequent. It seems that they existed always, but now the nature of these obligations has changed. From the abstract and common duty prescribed by law or religion, they turn into voluntarily accepted and specific in composition obligations. The term "compliance" is translated as consent or correspondence. Being derived from the verb to comply, it means the contractual relations, based on the adequacy of obligations to the desires and capabilities of the system (subject) that take them.

In a broad sense compliance means conforming to a rule such as specification, policy, standard or law. The very idea of compliance is realized in different forms: as a unified system (1), as regulatory rules (2), as forms of control (3). Thus, the system implies a set of methods that encourage actors to take compliance obligations. The regulatory compliance describes the goal, that the system (state or enterprise) aspire to achieve in their efforts to ensure that they are aware of and take steps to comply with regulative norms. Due to increasing number of regulations and need for operational transparency, systems are increasing adopting the use of consolidated and harmonized sets of control. Compliance-control is a corporate (state, regional) ideology aimed at promoting requirements for compliance of internal standards with generally accepted social norms. It can concern both technical (ecological) requirements and observance of social restrictions, but the first of the named ones do not fit into the subject of our article and we do not analyze them. Given the subject of the conference, the object of our research is, first of all, the corporation. Forms of state compliance are considered only as necessary, for example, when it comes to the process of institutionalizing practices as technologies for modern governance.

It is obvious that the initial theoretical construct was the theory of the "social contract", the arguments of which were used by Plato in his dialogues to explain the social interactions in the state. The case of Socrates, who allegedly refused to escape from his prison, is often described in the literature, arguing that by choosing Athens as the site of the settlement, he assumed the duty to pay taxes to the state's treasury, accordingly, he can expect protection and respect from him. The theory of the social contract in an abstract form explained the consent of people (citizens) to obey the law and the requirements of the state, receiving in return hope for order, protection from crime and other social guarantees. This idea was concretized by the representatives of the classical theory of the social contract showing each in its own way the effectiveness of the state system as a potential guarantor of compliance with norms.

Already in the works of Hobbes touched on delicate issue on compliance problem. He showed the complexity and multi-directional interests of individuals, groups, communities in connection with the establishment of typical forms of interaction (contracts). He stated that although compliance with contracts may be better for the group as a whole and it may be in an individual actor's best interest to agree to contracts, it may very well not be in his interest to actually comply with them (Hartz and Nielsen 2015). Following his logic the content of compliance should be constantly studied, monitor and used as a signal for agenda-setting. This profound remark, formulated by Hobbes for the theory of the social contract, perfectly explains the ideology of the compliance system. Carrying certain insignificant costs, restrictions, the individual as a part of the group will 
win in the end, without losing, for example, corruption, unethical behavior (stolen) and / or incompetence of employees.

The second direction, which can be considered as a source of compliance theory, is the economic theory of contracts. It deepened the abstract theory of the social contract by economic calculations, showing the wisdom of their compliance with the contract. Modern researchers of contractual relations have shown their feature as a constant unpredictability in relations, as obligations in the conditions of incomplete asymmetric information (i.e. in unpredictable situations). They enrich the understanding of the complexity of the compliance system, identifying and justifying the consequences of unfair behavior of actors, forming a modern understanding of the theory and structure of risks.

Let us also point to the psychological foreshortening of the compliance theory. It was just representatives of this sphere of science who were the first to use the term "compliance". Equally important is that they also studied the behavior of individuals in different situations: under the imposed and voluntarily accepted terms of the contract. They identified the phenomenon of opportunistic behavior as the most important factor that predetermines the effectiveness of compliance agreements. Therefore, the author of one of the works, considered now as classical one (Festinger and Carlsmith 1959), on an experimental basis estimated the readiness (in this case - students) to perform meaningless actions (winding the clock with one hand). The results of the research showed that only material rewards (even though a few dollars) formed an interest to the actions, and the bigger is the fee, the higher is the interest. Problems of differences in behavior with voluntarily / involuntarily taken obligations continue to attract psychologists up to now (Grabosky 1995). An example of the reflection on the imposed treaty (the manifestation of opportunistic behavior) at the state level can be considered Greece, when the country was tried to persuade to raise taxes from the population

The founder of the actual compliance theory in the organization is usually called Etzioni $(1964 ; 1975)$ who suggested from the standpoint of the contract to consider the enterprise (organization). He updated the focus on this field of managerial interactions and revealed in it the relations of compliance agreements. Thus, he revealed the common and distinctive property of all organizations - the artificiality of their creation that differ from natural ones: families, clans, tribes, so they may and should create them on stated goals. He classifies organizations by the types of power they use to direct the behavior of their members (coercive, utilitarian, normative) and the types of involvement of the participants (alienative, calculative, moral). For most organizations, according to the opinion of scientist, there are 3 types of norms (the principles of compliance of contracts) for regulating the relationship within the organization: coercive-alienative, utilitarian-calculative and based on norms of morality (normative-moral).

In accordance with the trend of development of social sciences, abstract discourses are replaced by impact analyses, which, in relation to contractual relations, means the transformation of the subject of study into an analysis of specific practices for implementing compliance contracts. They may have a different orientation, carrying out voluntary (although sometimes imposed from outside) obligations to comply with environmental, ethical, anti-corruption or other requirements. In exchange, the system that has taken them, in addition to their own moral satisfaction from the correctness of their actions, expects from other relationships more trust in themselves, and sometimes special preferences. These 3 types of contractual relations can be presented in the form of a table (see Table 1).

Table 1. The differences between 3 types of contract theory

\begin{tabular}{|c|c|c|c|}
\hline $\begin{array}{l}\text { Comparison } \\
\text { parameters }\end{array}$ & $\begin{array}{l}\text { The social } \\
\text { contract }\end{array}$ & $\begin{array}{l}\text { Contractual relations as a basic } \\
\text { form of social interaction }\end{array}$ & Compliance system \\
\hline $\begin{array}{l}\text { Sphere of } \\
\text { applications }\end{array}$ & Abstract theory & $\begin{array}{l}\text { The theory of the interaction of } \\
\text { social actors, especially within } \\
\text { the the institutional approach }\end{array}$ & $\begin{array}{l}\text { A modern theory that analyzes } \\
\text { specific practices (cases) of adopting } \\
\text { additional obligations of "right" } \\
\text { behavior }\end{array}$ \\
\hline $\begin{array}{l}\text { Contracting } \\
\text { agents }\end{array}$ & $\begin{array}{c}\text { Society and } \\
\text { citizens } \\
\text { (population) }\end{array}$ & $\begin{array}{c}\text { Subjects and objects of } \\
\text { governance (in theory and in } \\
\text { practice) }\end{array}$ & $\begin{array}{l}\text { Specific economic entities and society } \\
\text { (region, state) (1), relations between } \\
\text { the enterprise and employees (2) }\end{array}$ \\
\hline $\begin{array}{l}\text { The essence of } \\
\text { the theory (the } \\
\text { motive of } \\
\text { agreements) }\end{array}$ & $\begin{array}{l}\text { Compliance with } \\
\text { the law in } \\
\text { exchange for order } \\
\text { and protection }\end{array}$ & $\begin{array}{l}\text { The variety of forms of social } \\
\text { interaction, built on reciprocity } \\
\text { relations }\end{array}$ & $\begin{array}{l}\text { Voluntary and additional (in } \\
\text { comparison with other systems) } \\
\text { obligations in exchange for moral } \\
\text { satisfaction or public recognition. }\end{array}$ \\
\hline $\begin{array}{l}\text { Method of } \\
\text { motivation }\end{array}$ & $\begin{array}{l}\text { Fear of sanctions } \\
\text { in case of } \\
\text { violation of law, } \\
\text { the adoption of } \\
\text { norms as a result } \\
\text { of education }\end{array}$ & $\begin{array}{c}\text { Dissemination of institutional } \\
\text { practices as generally accepted } \\
\text { rules }\end{array}$ & $\begin{array}{l}\text { 1. Public recognition, positive image, } \\
\text { reputation, hope for preferences } \\
\text { 2. Obligatory condition of work in the } \\
\text { organization }\end{array}$ \\
\hline
\end{tabular}

Source: Own results 
Therefore, compliance theory is one of the directions of sociological theories. It can be regarded as the concretization and further development of the theories of the social contract, as well as the theory of social interactions, taking into account the fundamental difference of modern society from the preceding. Compliance theory involves consciously taken, as a rule, additional obligations to overcome social risks (corruption, inefficient and/or antisocial management, etc.). The intellectual (scientific) potential of society and the conscious socially oriented behavior of the majority of people make it possible to design new technologies of social management by means of which it is possible to resist social "diseases" in the form of consequences of "bad" behavior: mercenary or incompetent professional actions.

Modern researchers of compliance theory associate it with a goal-oriented approach (Lindengerg 1993). According to Coombs (1980), "compliance must be understood as behavior that corresponds to expectations reported to regulators as to how the first should or should not behave in a given area". Another researcher (Hutter 1997) writes: "compliance is compliance with the law", meaning that the standards of conduct have long been developed, the problem is that they are strictly enforced.

Modern research, as a rule, focuses more on managed, rather than immanent for the system behavior. At the same time, a combination of many factors that form the patterns of behavior of actors described by different sciences and therefore evaluated by different methods seriously hampers their understanding. One cannot but agree with Etienne (2010), who singled out 2 circumstances. The first is the multiplicity of goals, as a circle of desired regulatory outcomes. Their frequent heterogeneity and often multi-directionality (which is more than explainable with respect to any type of system) hampers both the formation of a unified strategy for the behavior of the object and hinders the evaluation of the effectiveness of measures. To overcome complexity, some researchers propose a simplification, reducing it (multiplicity) to two models that formulate a goal: utilitarian and moral (Kagan and Scholz 1984). Many researchers have attempted to compare the "strength" of these two basic causes, but, according to Etienne (1997), they did not receive a definitive answer. The second is an explanation of the process of formation of altruistic (ethical) behavior or the process of reconstruction ("displacement") of selfish behavior by "internal" goals, such as altruism, duty or trust. Again, the researches exist and numerous ones (Bowls 2008; or Frei 1997) but they do not give a complete answer. Moreover, emotional forms of behavior have remained practically unexplored.

Seeing the plurality and heterogeneity of motivations, some researchers are trying to build a taxonomy of goals. Thus, Lindengerg (1993) singled out: hedonic, material (revenue) and normative. Other authors have identified preferences between them: highlighting the main and secondary, narrow and broad (Wenzel 2004). The third group of researchers analyzed the regulatory mechanisms: more or less difficult to achieve (Hutter 2001), it revealed the stages of formation: signaling goals, expecting consequences as a way of determining preferences or estimating the price - conditional prizes of pleasures (Mitchel 1994), as well as their situation, personal characteristics (Lessig 1995).

These theories show an active study of compliance contracts and in the modern trend - the maximum approximation to the object of study, i.e. on specific cases experimentally. Even if the researchers do not receive a definitive answer, they indicate the complexity of the process, reveal new factors of influence. In addition, they show that the compliance system abroad is not implemented easily and without problems too. There are theoretical works that regard it as a new religion and, accordingly, as the form of new coercion. However, the study showed (Trevino et al. 2014) that people are less deceived in organizations where the ethical climate is let in the form of compliance monitoring. Moreover, scientists have fixed the fact that in developed countries, in general, managers responsible for this campaign view it as an additional inconvenience. Many workers consider themselves quite ethically educated, they learn the rules of behavior at school, university, as well as within the framework of religion and culture and actively advocate against the compliance control (Langewoort 2015). It seems that the variety of approaches is a confirmation of scientific character, it helps to consider the specifics, national culture and the characteristics of organizations.

\section{Institutional milestones in the formation of compliance control}

It seems that the formation of practices for the interaction of actors identified from the standpoint of contract compliances can be dated to the second half of the twentieth century, i.e. the period of the formation of a postmodern society. It was embodied in the development of forms of social and state regulation that emerged and became stronger after the Second World War, as a reflection of the effectiveness of joint efforts in the struggle against the enemy (the success of the Marshall Plan in the United States) and the organized restoration of destroyed farms (as it happened, for example, in post-war Germany).

At the same time scientists as one of the first forms of state control called the regulation of the quality of food and medical products. As early as in 1906, the Food and Drug Administration was established in the United States. Later, this organization was transformed into a Consumer Product Safety Authority, which has organized and is still implementing government control. Mass media initiated, technologies for controlling harmful industries (for example, oil), as well as the quality of medicines and foodstuffs, have become the beginning of 
institutionalizing control relationships between the state and business. It is clear that here we can see examples of expansion of the possibilities of the state administration, but not directly compliance control, still it identified the state's potential as the organizer of new practices and regulatory methods.

In the wave of administrative reforms, intentions have also intensified to increase the role of regulation in general and in group behavior (firms, organizations, regions) in particular. For example, in the United States in the year 1970, the fight against corruption was actualized, the Foreign Corrupt Practice Act (FCPA), which sets out ethical principles, was adopted. It is accepted to consider this law the first compliment of the program, which has recognized unlawful for an U.S. citizen, and certain foreign issuers of securities to make a corrupt payment to a foreign official for the purpose of obtaining or retaining business or selling business to any other person.

An Association of Sponsorship Organizations was created to stimulate the necessary political (anticorruption) course of the Government, which conditioned the submission of firms to FCPA conditions. The further development of the practice of compliance was the adoption by the US Congress in 1984 of Sentencing Reform act, which created a set of mandatory federal sentencing Guidelines. They formed and delegated the responsibility to provide certainty and fairness in sentencing to avoid unwarranted disparities while maintaining sufficient flexibility to permit individualized sentencing when warranted by mitigating or aggravating factors. It formulates the responsibility for ensuring certainty and justice in sentencing to avoid unjustified disparities while maintaining sufficient flexibility to allow individual sentences to be imposed when justified by mitigating or aggravating circumstances. In 2004, this law was extended. Two basic standards were identified: the need for directors and executives to play an active role in adhering to it, as well as the importance of promoting the organizational culture of the enterprise. Thus, the FCPA has become synonymous with an effective compliance program.

Sarbanes Oxley Act SOX (2002) has continued and deepened the line of government control over financial operations and their purity. He tightened the requirements for financial reporting and the process of its preparation, reflecting anti-corruption measures, taking into account the many scandals and devastation of large corporations (and, accordingly, their shareholders) by that time due to the "unethical behavior" of their major managers. The tightening of requirements became mandatory for all participants (issuers of the US Securities Commission - Security and Exchange Commission, SEC). It contains 11 points, ranging from additional responsibilities to criminal penalties up to Penal Reform Law. It also introduced new conditions for monitoring a special agency Public company accounting Oversight Board, which operated in parallel with independent auditing firms, government and international valuation organizations. Numerous amendments to the law extended its effect to other enterprises (404 - for small enterprises), deepened the forms of influence (302 introduced a requirement for openness of internal control, 303 - improper influence on the actions of the auditors, 401 - disclosures on periodic reports (Off-balance Sheet items), 404 - assessment of internal Control, 802 - criminal penalties for influencing US agency, 806 - civil actions to protect against retaliation in fraud cases, 906 - criminal penalties for CEO/CFO financial statement certification, 1107 - criminal penalties for retaliation against whistleblowers). This example of regulation was practically immediately distributed to Canada, Germany, South Africa (2002), France (2003), Australia (2004), India (2005), Japan (2006), as well as Denmark, Turkey and other countries.

It seems that the next step in the process of institutionalizing the practice of compliance-systems was the formation of a single international strategy, its regulatory. Thus, in the 21 st century a number of conventions to be ratified were adopted, as well as the recommendations prescribed by authoritative international organizations for implementation in the system of national legislation. The first examples are the UN Convention against Corruption (2003), UN Minimum Rules for the Treatment of Prisoners (Nelson Mandela's Rules) (2015), the United Nations Framework Convention on Climate Change, 1992, etc. They created the background for the implementation of ethical programs on the one hand, and on the other - they pushing States less active in solving this circle of problems to their solution.

Thus, Table 2 provides guidance for the Russian Federation on the necessity of bringing its legislation in line with modern international principles. For the most part, the proposals are accepted and the laws are being improved. Nevertheless, there are a number of issues on which Russia disagrees with the recommendations put forward. This applies, first of all, to proposals for the criminalization of "sentence" and "promise" of bribes, the refusal of the institution of active repentance, and the extension of the limitation period for crimes of minor gravity as separate offenses. On these issues, it is necessary to further harmonize the positions of Russia and the OECD, as reflected in the Report on research investigation (Gohberg and Meshkova 2013).

At the same time, important documents are adopted regulating foreign trade, financial and tax matters. So, in 2013, the Customs Code of the Customs Union in the EU was adopted. In 2008, within the framework of the 3rd Basel Accord, new requirements were set for banks and their reliability, and from 2013, the transition to new standards began. In 1993, the Fundamentals of the Uniform World Tax Code were developed, which are constantly updated with new articles, for example, "the application of tax evasion measures for taxpayers using schemes involving the company and international trusts established in offshore zones and countries (territories) with preferential tax regimes, etc. 
Table 2. List of recommendations with an assessment of the level of their implementation in the Russian legislative system

\begin{tabular}{|l|l|}
\hline The title of the document which is recommended for being corrected & \\
\hline $\begin{array}{l}\text { Convention on Combating Bribery of Foreign Public Officials in International Business } \\
\text { Transactions ( 21.11. 1997) }\end{array}$ & Adopted \\
\hline $\begin{array}{l}\text { Recommendation of the Council on Combating Bribery in International Business } \\
\text { Transactions (1997) }\end{array}$ & At the stage of agreement \\
\hline $\begin{array}{l}\text { Recommendation of the Council on Bribery and Officially Supported Export Credits } \\
(2006)\end{array}$ & Adopted \\
\hline $\begin{array}{l}\text { Recommendation of the Council on the Tax Deductibility of Bribes to Foreign Public } \\
\text { Officials (1996) }\end{array}$ & Adopted \\
\hline Recommendation on Anti-Corruption Proposals for Bilateral Aid Procurement (1996) & At the stage of agreement \\
\hline $\begin{array}{l}\text { Recommendation of the Council on OECD Guidelines for Managing Conflict of Interest } \\
\text { in the Public Service (2003) }\end{array}$ & At the stage of adoption \\
\hline
\end{tabular}

Source: Own results

Thus, the United Nations documents (United Nations 2013) fixed unified principles for all enterprises implementing a compliance system: independence (i.e. autonomy of services from the main office), official status (recognition of the role in the organization), clear (obligatory and regular) accountability of employees to the service of the Criminal Code, the elimination of a conflict of interest, access to internal information, interaction with regulators. 12 assessment principles (risk assessment) have been identified for assessing the level of compliance-management in enterprises, which suggest possible evaluations: "yes", "no", "in the stage of implementation" (in the stage of agreement):

1. The company conducts a standard risk assessment on a regular basis (at least annual),

2. The company identifies operational roles and responsibilities in charge of conduct the risk assessment,

3. The company defines and documents operational process for conduction the risk assessment,

4. The company defines oversight responsibilities,

5. The company embeds the risk assessment in existing processes,

6. The company is aware of negative consequences of failing to prevent corruption (legal, commercial and operational, reputational risks),

7. The risk assessment includes all major areas of risk (e.g. industrial and geographical location),

8. The company identifies corruption related risks by using internal or external sources,

9. The company defines priorities based on overall risk exposure,

10. The company develops a risk strategy to minimize the overall risk exposure and identifies residential risks,

11. The company documents the outcomes of the overall risk assessment,

12. The company reports publicly on its risk assessment.

The United Nations (2013) document has also been developed checklists of estimation of high-ranking managers, of developing of anti-corruption program (p. 28), of oversight of anti-corruption program (p. 32), clear, visible and accessible policy prohibiting corruption (p. 38), facilitation payments (p. 42), special types of expenditures (p. 48), conflicts of interest (p. 53), application of anti-corruption program to business partners (p. 62), internal controls and recording keeping (p. 68), communication and training (p. 73), promoting and incentivizing ethic and compliance (p. 79), seeking guidance - detecting and reporting violations (p. 85), addressing violations (p. 95), periodic reviews and evaluations of the anti-corruption program (p. 102).

Thus, the institute of compliance-system, despite the relatively short period of its existence, can be considered to have developed (for some countries of the world). As individual attempts at developing control practices, its initial principles began to form at the beginning of the twentieth century, but as a separate and widespread institution of social management, aimed at overcoming the risks at the enterprise, it arose in the 1970s. The course of its institutionalization can be characterized by the rapid pace of spreading around the world (1) and areas of control (first harmful production and quality of food and medicine, then tightening of financial control, further development of customs and environmental regulation along with the formation of anticorruption behavior at the enterprise) (2), as well as the transition from the national level of regulatory control to the international (3). It is equally important to improve the internal content of the institute: the constant development of the legislative base and its dissemination to national and international system of laws, the search for forms of implementation in management practice, including control: creation of special services, adoption of internal codes of the enterprise, development of the system of training and certification, conducting international comparative rating and rating. At the same time, the culture of "correct" behavior of workers and the population 
as a whole is formed, which, according to experts, reveals certain regulatory areas, where this institution becomes unnecessary, as the norms of legislation are not violated.

\section{Ethical (anti-corruption) compliance in the Russian Federation}

Separate manifestations of control over the observance of ethical standards existed in the USSR, and they acted rather effectively. The rules of "correct" behavior as part of communist's duties were broadcast on national channels of education, ideology and culture. The codes of "the builders of communism", the rules of ethical behavior existed in almost every enterprise. In certain periods (the years of "Stalinism", 30-40 years) they turned into a form of state terror in the struggle against minor mischief, which could not always be justified, given the low level of living and the shortage of products and goods, However, rigid centralized and public control minimized the area of corruption, reducing it to the sphere of consumption - trade, distribution of public goods (housing, cars, passes in a sanatorium, etc.).

With the collapse of the USSR, a state based on centralized governance and regulation, taking into account the enormous public property and goods that remained without the owner, the country was overwhelmed with corruption and offenses. At present, as the horizontal control system has been formed, the field for violations has partially decreased. In the country, laws that prohibit corruption and deviation from ethical norms are adopted and in force. Corruption is recognized as the No1 risk in the country. Each enterprise (authority) has developed a website or other forms for gathering information on ethical violations. All major actions and/or events (meetings of company managers, final examination at schools, defense of dissertations, etc.) have become public: they are necessarily recorded and displayed on an open site, each resident has access to them. In the authorities, ethical committees of different purposes: from the struggle with the offenders of discipline to the prevention of situations with a conflict of interests - have been created.

It is believed that corruption in the country is mainly localized by separate spheres: senior management and executive authorities, foreign economic activity, the financial sphere and others, where public control is difficult. Taking into account the significance of the mentioned segments, the anti-corruption indicators remain low, respectively, the country occupies one of the last places in the world rating by Transparency International. Thus, Russian Federation occupies approximately 140 position out of 180 and the perception of the effectiveness of the fight against corruption is estimated by the population in 28 out of 100 possible in the period from 2012 to 2017.

To organize the fight against corruption at the enterprise, but mainly for the formation of anticorruption culture among population is trying to introduce the experience of compliance control. As a rule its occurrence dates back to 2013. However, as one of the areas of corporate ideology, it arose in the Russian Federation in mid-1999, when the Central Bank Decree No-603 "On the Procedure for the Implementation of Internal Control over the Correspondence of Activities in Financial Markets to the Law on Financial Markets in Credit Institutions" was adopted. This document first introduced a new term and, although at this stage it was supposed to use it only in the financial sphere. Within the framework of the decree, the term "compliance control" was considered as "monitoring of the internal character, allowing to control the work of the financial sector for the purpose of its compliance with the current legislation". Recognition of this as an element of state control did not last long. In 2004, the decree of the Central Bank was canceled, although the term itself is preserved and even extends its scope.

Following the United Nations (2013) recommendations, the Russian authorities also consider the following types of risks as the area of influence of the compliance control: violation of compliance with legal requirements (1), financial manipulation (2), abuse of office (corruption) (3), lack of professionalism and low competence of employees (4), cases of raider seizures, theft, withdrawal of financial resources (5), threat of business reputation (6), etc.

Implementation of compliance control takes place in the following areas: from the beginning of the $21^{\text {st }}$ century it has been introduced at the enterprises of the financial sector and foreign trade. In the financial sector this was due to huge budget losses from the withdrawal of money; in foreign trade - at the request of foreign partners. However, out of the seven methods of compliance control applied in the EU: preliminary information, joint inspections of state control and oversight bodies, conclusion of auditors of the organization, verification of corporate data, analysis of outstanding court decisions, formation of a positive reputation, anticorruption corporate culture, in the RF is actively using only the first two.

One cannot but acknowledge the low level of the spread of compliance control in the Russia. Enterprises do not recognize its significance and see - to our mining it is reasonable - some increase in costs. Accordingly, its introduction in the non-financial sphere is carried out only by companies that are affiliated with the West or those who want to enter the foreign market. In general, compliance control did not become a mass practice in the country and affected 2-3 dozen enterprises. Among them: MTS (telecommunication corporation which introduced this technology from the desire to sell its company's shares on the New York Stock Exchange now 
$1 / 3$ of the company's shares are posted on the Exchange's website), as well as PJSC "Vimpelcom", Roskosmos corporation, KAMAZ, Dixie, Beeline, Norilsk Nickel, Rosatom, Orange, or Rostelecom.

In 2012, a national compliance control Association was created. The company was headed by Balakin VV, who trained abroad. Its creation was initiated by the three founding organizations: OOO Masinoexport, National Legal Network CJSC, Alternative Investment Consulting Center for Investment Risk Analysis LLC, which have already started applying compliance-control system. The Association assumed the role of advocating a new management method in the corporation, training employees in new conditions, auditing. The Association holds web-based seminars and coaching trainings, organizes schools for the dissemination of best practices and conferences.

Here are some of the characteristics of the problems that MTS has encountered when introducing the technology. According to the director of the department responsible for the introduction of the named technology at the enterprise (Romashkina 2016). Its introduction began in 2000 and in 2012 a special unit was formed, which included 12 people. She faced problems - they are mostly in a general cultural nature: the approach to corruption as a natural and unbridled evil is dominant in the country (1), it is customary to "act bypassing the law" (2), the principle of personal responsibility of managers is not welcomed (3), many systems are perceived as additional bureaucratic procedure (4), the department requires costs, and it is extremely difficult to find them, especially during the crisis period (5). Romashkina (2016) highlighted the main method of implementation - the development of individual KPI compliance control and their inclusion in the system of annual performance indicators for all employees. Obligatory observance of norms is included in the list of positions of an employment contract with an employee.

An important feature of compliance control in the Russian Federation is the lack of its representation in the scientific field. It is possible to name only 10 publications, for example (Akhunyanova and Ermakova 2014; Malykhin 2009; Tkachenko and Shevchenko 2016; Yudenkov 2012), which cover its theory and practice of implementation. The reason for this is the specifics of the Russian field: ethical (anti-corruption) problems have not become social problems. The media tries not to voice them, and for enterprises it is more important to establish relations with the leadership of the country than to form a positive image in the eyes of the public. Enterprises are aware not only of the anti-social, but also of the unprofitable nature of their current strategy. The peculiarity of the introduction of the new technology remains unilluminated, additional costs are not revealed, the results are not named. Only one work described a specific manifestation, arguing the economic feasibility of technology - the growth of the company's value (Aleshin and Aleshina 2016).

Let's give some data in the course of the survey conducted by KPMG in Russia. The survey is based on face-to-face interview with 42 specialists in compliance, who agreed to participate in it. Their answers state the fact that the autonomous specialized service exists only at 33 companies. The areas where technology was most widely used: telecom and media (24\%), oil and gas (19), pharmaceutical (17), innovation and technology (14), consumer products (12), mining (5), transportation (5), automotive (2), utilities (2) (Global Compliance Survey 2016 , p. 3). Areas of compliance were identified as: anticorruption and ethical standards (100\%), compliance in healthy, wealth and environment (97), antimonopoly (85), human rights in the workplace (67), in personal and confidential data protection (61), compliance with trade sanctions (45), anti-money-laundering and terrorism financing (24), compliance in the marketing products sector (9) (Global Compliance Survey 2016, p. 5). Main methods of functioning in organizations were mentioned: consultation on compliance and ethical business standards, trainings, initial reviews on massages received by hotlines, hotline, investigation on compliance breaches, including corruption cases, the identification of the conflict of interest, violations of ethical business standards.

According to KPMG (Global Compliance Survey 2016), 46\% of Russian corporations are abusive (expressed in the form of misappropriation of assets and revenues of the company); in $11 \%$ financial statements are distorted and bribes are given. Every fourth company annually loses more than $\$ 1$ million from such violations. In $71 \%$ of cases, these losses are due to the weakness of internal control. Surveys conducted by a well-known audit firm in the Russian Federation (PwC) revealed the following drawbacks: in $80 \%$ of companies, one of the main areas of compliance control is the monitoring of compliance with procurement standards with only $25 \%$ of them in the monitoring committee are experts in supply areas.

\section{Conclusions}

All in all, one can conclude that the introduction of compliance-control of the compliance systems in the Russian Federation still remains at a formation stage. Whether by characterizing introduction of this technology abroad it is possible to speak about formation of culture of management (first of all in corporations), then in the Russian Federation one can see that it is all about the about the beginning of distribution within the internal realm and intended for the practicians. 
As it stems from the report conducted by $\mathrm{PwC}$ in the Russian Federation, compliance-control did not become manifestation of corporate responsibility as, for example, participation in charity, cooperation with local government, openness of tax policy.

\section{Acknowledgements}

The paper was funded by and prepared within implementation of the "Social Technologies of Formation of Anticorruption Climate in the Russian Society” project (project ID 27528351).

\section{References}

Akhunyanova ChF, Ermakova NA (2014) Komplayens-kontrol. Koncepcii ustoichivogo razvitiya korporacij. Mezdunarodnyi bukhgalterskii uchet 3(297):1-10.

Aleshin M, Aleshina EI (2016) Komplayens kak instrument povysheniya stoimosti korporacij. Naukovedenie 8 (5):1-10.

Bowls S (2008) Policies Designed for Self-interested Citizens May Undermine the Moral Sentiments: Evidence from Economic Experiments. Science 320 (5883):1605-09. doi: 10.1126/science.1152110

Bychkova S, Makarova N, Zhidkova E (2018). Measurement of information in the subsystem of internal control of the controlling system of organizations of the agro-industrial complex. Entrepreneurship and Sustainability Issues 6(1):35-43. doi: 10.9770/jesi.2018.6.1(3)

Coombs FS (1980) The bases of Noncompliance with a Policy. Policy Studies Journal 8(6):885-892. doi:10.1111/j.1541-0072.1980.tb01179.x

Doležal J, Šnajdr J, Belás J, Vincúrová Z (2015) Model of the loan process in the context of unrealized income and loss prevention. Journal of International Studies 8(1):91-106. doi: 10.14254/2071-8330.2015/8-1/8

Etienne J (2011) Compliance theory: a goal framing approach. Law \& Policy 33(3):305-333. doi: 10.1111/j.1467-9930.2011.00340.x

Etzioni A, A comprehensive analyses of complex Organizations, 1st edn. (Free Press: NY, USA, 1975), 584 p.

Etzioni A, Modern Organizations, 1st edn. (Englewood Cliffs, NJ: Prentice Hall, 1964), 120 p.

Filipishyna L, Bessonova S, Venckeviciute G (2018) Integral assessment of developmental stability: cases of Lithuania and Ukraine. Entrepreneurship and Sustainability Issues 6(1):87-99. doi: 10.9770/jesi.2018.6.1(7)

Festinger L, Carlsmith JM (1959) Cognitive consequences of forced compliance. The Journal of Abnormal and Social Psychology 58 (2): 203-210. doi: 10.1037/h0041593

Frei B, Not just for the money: An economic theory of Personal motivation, 1st edn. (Edgar Elgar Publishing: Cheltenham, 1997), $168 \mathrm{p}$.

Global Compliance Survey (2016) https://assets.kpmg.com/content/dam/kpmg/ru/pdf/2017/07/ru-eninternational-compliance-survey/22.pdf Accessed 27 Aug 2018

Gohberg LM, Meshkova TA, Otchet o nauchno-issledovatel'skoj rabote «Ocenka posledstvij prisoedineniya Rossii k OEHSR (zaklyuchitel'nyj etap ), T. 1. (Vysshaya shkola ehkonomiki: Moskva, 2013), 1064 p.

Grabosky P (1995) Counterproductive regulation. International Journal of the Sociology of Law 23(4): 347-369. doi: 10.1016/s0194-6595(05)80003-6

Hartz E, Nielsen CF (2015) From conditions of equality to demands of justice: equal freedom, motivation and justification in Hobbes, Rousseau and Rawls. Critical Review of International Social and Political Philosophy 18(1):7-2. doi:10.1080/13698230.2014.995498

Hutter B, Compliance: regulation and environment. Oxford socio-legal studies, 1st edn. (Oxford University Press: Oxford, UK, 1997), 302 p.

Hutter B, Regulation and risk: occupational health and safety on railways,1st edn. (Oxford University Press: Oxford, 2001), 301 p. 
Kagan R, Scholz J (1984) The Criminology of the Corporation and Regulatory Enforcement Strategies. In Enforcing Regulation 67 - 95 p. doi: 10.1007/978-94-017-5297-8_4

Langewoort D, Behavioral Ethics, behavioral compliance. Handbook on Corporate Crime and Financial Misdealing, 1st edn. (eds. by J.Arlen and E.Elgar: Georgetown University, 2015), p. 263-280.

Lessig L (1995) The regulation of Social Meaning. University of Chicago Law Review 62(3): 943 - 1045. doi: $10.2307 / 1600054$

Lindengerg S (1993) Framing, Empirical evidence and applications. Jahrbuch fur Neue Politische Oconomie, Tubengen, Mohr (Siebeck), pp. 11-35.

Malykhin DV (2009) Osobennosti organizacii komplayens-kontrolya v rossijskih bankah. Vnutrennij kontrol v kreditnoi organizacii 2:32-36.

Mitchel R, International oil pollution at sea, 1st edn. (the MIT Press: Cambridge, 1994), 368 p.

Romashkina YU (2016) Komplaens i antikorrupciya. Prakticheskiy opyt PAO "MTS". https://docplayer.ru/59061663-Komplaens-i-antikorrupciya-prakticheskiy-opyt-pao-mts.html Accessed 05 Sep 2018

Tkachenko YuA, Shevchenko MV (2016) Komplayens-kontrol kak klyuchevoi factor v upravlenii ehkonomicheskim sub"ektom. Vestnik BGTU im. V.G. Shukhova 2:196 - 200.

Trevino LK, Nieuwenboer N, Kish-Gephart J (2014) (Un)Ethical behavior in organizations. Annual Review on Psychology 65 (1):635-660. doi: 10.1146/annurev-psych-113011-143745

United Nations (2013) An anti-corruption ethics and complaints program to business: a practical guide, 1 st edn. (United Nations Office on Drugs and Crime: Vienna, 2013), 107 p.

Ushakov D, Bandurina N, Shkodinsky S (2017) Country's Welfare as an Efficiency Factor in Fiscal Policy Promoting Economic Growth. Montenegrin Journal of Economics 13(2):121-127. doi: 10.14254/1800$5845 / 2017.13-2.7$

Wenzel M (2004) The social side of sanctions: Personal and social norms as moderators of Deterrence. Law and Human Behavior 28(5): 547 - 567. doi: 10.1023/b:lahu.0000046433.57588.71

Yudenkov YN (2012) Razvitie komplajens-kontrolya v rossijskih kreditnyh organizaciyah [Development of compliance control in Russian credit companies]. Voprosy ehkonomiki i prava 12 (1): 140-145. 